\title{
Peculiaridades entre Conselho Tutelar \\ E CRIANÇAS ENCAMINHADAS PELA ESCOLA
}

\author{
Priscila Valverde Fernandes ${ }^{\star}$ \\ Elizabeth Maria Andrade Aragão ${ }^{\star}$
}

\begin{abstract}
RESUMO
Este artigo se propõe a considerar as peculiaridades da relação entre o Conselho Tutelar e as crianças que foram encaminhadas a este órgão pela escola no municipio de Cariacica-ES. A partir do método qualitativo, priorizou-se o estudo com conselheiras tutelares tentando apreender, por meio de suas experiências, como descrevem o atendimento dado às crianças que lhes são encaminhadas. O referencial teórico que sustentou o trabalho aproximou-se de autores que compartilham, juntamente com Foucault, da ideia de uma história que pode ser abordada numa perspectiva genealógica permitindo-nos a visibilidade dos mais variados saberes existentes em um determinado espaço e momento social. Foram realizadas entrevistas semiestruturadas com quatro conselheiras. Na análise, pode-se constatar processos de psicologização, a presença da formulação de um discurso competente baseado no intimismo e no familiarismo e a formação de um campo de forças entre escola e conselho, no qual a criança tem, em geral, seu comportamento tido como inaceitável.
\end{abstract}

Palavras-chaves: Conselho Tutelar; criança; familia. escola.

\section{Particularities between Tutorial Council AND CHILDREN SENT BY THE SCHOOLS}

\begin{abstract}
This article aims at the particularities concerning the Tutorial Council and children that were sent by their schools from the city of Cariacica ES to this institution. From this qualitative method, the study with the tutorial counselors was prioritized in an attempt to learn, through their experiences how to describe the assistance given to the children brought to them. The theoretical reference works with authors that share the idea of a story that can be approached in a genealogical perspective, together with Foucault, that allows a vision of a

\footnotetext{
^Psicóloga, Mestre em Psicologia Institucional pela Universidade Federal do Espírito Santo.

E-mail: privalverde@hotmail.com Programa de Pós-Graduação em Psicologia Institucional.

E-mail: baragao@terra.com.br
}

$\star \star$ Professora do Departamento de Psicologia da Universidade Federal do Espírito Santo e do
\end{abstract}


wide variety of knowledge existing in a determined space and social moment. Interviews were made with four counselors. Through the analysis, it comes a relation marked by psychology, competent speech, proximity, familiarization and the formation of a strength field among the schools and the Tutorial Council, on which most of the times, the child's behavior is considered unacceptable.

Keywords: Tutorial Council; child; family; school.

\section{INTRODUÇÃo}

Para que possamos nos aproximar das práticas que se efetivam em um Conselho Tutelar faz-se necessário levar em conta os processos históricos que sustentam sua própria formulação. Dessa forma, observa-se que, tanto o Conselho Tutelar como o Conselho Municipal de Direitos da Criança e do Adolescente, sobressaem como órgãos instituídos a partir do Estatuto da Criança e do Adolescente com o objetivo de se constituírem como dispositivos legais específicos para proteção dos direitos infantojuvenis. Suas prescrições formais encontram-se ditadas no texto da lei, entretanto, suas configurações institucionais e funcionais precisam ser constantemente acompanhadas para serem, de fato, compreendidas e, quando necessário, revisadas em função da pretensão de avanço que se quer do cumprimento de proteção de direitos.

Considerando que a partir do Estatuto uma nova realidade da criança e do adolescente começou a ser delineada em superação às tradicionais práticas assistencialistas que lhes eram destinadas, importa tentar apreender como nos espaços mais cotidianos esse anseio tem-se construído. Em nosso estudo, nossa atenção voltou-se para a relação escola - Conselho Tutelar.

Essa relação vem-se estabelecendo desde 1990, com maior ou menor intensidade nos diferentes municípios brasileiros. Neste sentido, pode-se dizer que o Conselho Tutelar e a escola têm se encontrado de diversas formas, em diferentes momentos, compondo particularidades e configurações. Consequentemente, por conta dessa interação tem-se produzido inúmeras práticas, tanto na escola quanto no Conselho Tutelar, que compreendem a criança ora como sujeito de direitos, ora como objeto de intervenção.

É nesse caminho que nos propomos a discutir sobre as peculiaridades da relação entre o Conselho Tutelar e as crianças encaminhadas pela escola a esse órgão. Com esse propósito, o estudo se efetivou a partir do contato com conselheiras tutelares que participaram do mandato de 2005 a 2007 no município de Cariacica, Espírito Santo.

Para este estudo, buscamos o apoio e a contribuição de diversos autores. Escolhemos, como nosso referencial teórico, autores que compartilham, juntamente com Foucault (2008), da ideia de uma história que pode ser abordada numa perspectiva genealógica, ${ }^{1}$ que nos permite a visibilidade dos mais variados sabe- 
res existentes em um determinado espaço e momento social. Isso quer dizer que nos propomos a fazer a análise da gênese e não da origem dessas relações que têm sido estabelecidas entre Conselho Tutelar e a escola.

\section{O Município de Cariacica}

Cariacica é parte integrante da Região Metropolitana da Grande Vitória e se caracteriza como o segundo município mais populoso do Estado com 356.536 habitantes, conforme o Instituto Brasileiro de Geografia e Estatística (IBGE, 2007). Também, desponta como o terceiro município com os grandes desafios sociais, políticos e econômicos no contexto do Estado do Espírito Santo.

O município, na década de 1970, passou a ser conhecido como espaço dos rejeitados em função do intenso fluxo de migrantes que acolheu e dos bolsões de miséria que se formaram em seu território, entendido como periferia da capital do estado. Esses migrantes eram, em sua maioria, pessoas vindas do interior do próprio Estado, do sul da Bahia e de Minas Gerais.

Por conta desse desmedido fluxo migratório, o município foi sendo ocupado indiscriminadamente por habitações clandestinas e por loteamentos sem infraestrutura básica como ordenamento e calçamento de ruas, rede de água e esgoto, equipamentos sociais etc. Além disso, o município experimentou em sua história o lugar do "canto dos enjeitados", por abarcar estabelecimentos que reforçam a visão de uma dinâmica excludente. Estabelecimentos tais como o Manicômio Judiciário, o Instituto Espírito-Santense de Bem-Estar do Menor (IESBEM-ES), ${ }^{2}$ a Penitenciária Feminina, o Hospital Psiquiátrico Adauto Botelho, o Hospital Pedro Fontes (antigo Leprosário) e o Orfanato Cristo Rei.

Paralelamente à expansão demográfica, a história política de Cariacica desde os anos de 1970 foi marcada por uma série de conturbações. Ocorrências de toda ordem, como exemplo, assassinatos de homens públicos, afastamentos de autoridades por acusação de irregularidades administrativas, cassações de mandato de ocupantes de cargos eletivos, dentre outros. A história do município e os efeitos dos acontecimentos que a constituíram têm provocado um cenário de violência que sobressai como uma de suas mais significativas marcas. Durante as décadas de 1980 e 1990, Cariacica passou a ser conhecido como o município mais violento do estado.

Atualmente, Cariacica vem recebendo muitos investimentos e com o Orçamento Participativo ${ }^{3}$ tem realizado obras que são votadas e definidas pela própria população. Para os investidores, o Poder Público municipal vem promovendo ações de infraestrutura e tem buscado o desenvolvimento das empresas e de novos negócios que, de forma direta e indireta, em muitos casos, nessa região, tem contribuído para a melhoria da vida dos moradores do município.

\section{O Percurso metodológico}

$\mathrm{Na}$ escolha do método, escolhemos instrumentos que nos auxiliaram no entendimento de uma história não linear e impossível de ser apreendida como causa-efeito, principalmente quando consideramos certos serviços públicos e a própria realidade de Cariacica. Dessa forma, utilizamos a pesquisa qualitativa, ${ }^{4}$ com o intuito de acompanhar os movimentos do campo pesquisado. 
Organizamos, então, um roteiro que indicou uma primeira direção. Permanecemos abertos às variações, entendendo a inexistência de exigências a priori. Compreendemos essas variações a partir da cartografia, que é uma prática geográfica de acompanhamento de processos em curso que, mais do que de um traçado de percursos históricos, ocupa-se de um campo de forças no seio mesmo dos estratos. A partir Gilles Deleuze e Félix Guattari (1995), segundo Kastrup (2007), a cartografia se oferece como trilha para acessar aquilo que força a pensar, dando-se ao pesquisador, como possibilidade de acompanhamento daquilo que não se curva à representação. Dessa forma, nosso primeiro roteiro foi se definindo e redefinindo constantemente conforme as paisagens se organizavam e, dessa forma, fomos acompanhando os processos.

Com o intuito de questionar a linearidade da história, percorremos nosso caminho com a ideia da genealogia foucaultiana, uma ferramenta que "[...] trabalha com pergaminhos embaralhados, riscados, várias vezes reescritos" (FOUCAULT, 2008, p. 15) e que nos auxiliou em todo o processo. Foi assim que, caminhando por uma história não oficial, narrada por personagens que desempenharam papéis distintos e/ou foram excluídos do discurso dito verdadeiro, que tentamos buscar a singularidade dos acontecimentos. Esta singularidade foi buscada, sobretudo, naquilo que geralmente não participa da história, como exemplo "[...] os sentimentos, o amor, a consciência, os instintos" (FOUCAULT, 2008, p. 15), que nos levam a entender alguns fatos que diversas vezes são excluídos, desconsiderados, desvalorizados e mesmo apagados do discurso oficial.

$\mathrm{Na}$ genealogia, Foucault (2008) trata do lugar onde os acontecimentos são acasos e não causalidades. A genealogia agita, fragmenta e heterogeniza os fatos. Ele ainda nos mostra "[...] que na raiz daquilo que nós conhecemos e daquilo que nós somos - não existem a verdade e o ser, mas a exterioridade do acidente" (FOUCAULT, 2008, p. 31).

A história também é emergência. Isto é,

[...] enquanto que a proveniência designa a qualidade de um instinto, seu grau ou seu desfalecimento, e a marca que ele deixa no corpo, a emergência designa um lugar de afrontamento (FOUCAULT, 2008, p. 24).

A emergência, portanto, fala do combate frente às circunstâncias adversas.

Dessa forma, entrevistamos as conselheiras tutelares do mandato de 2005 a 2007. Com intuito de compreendermos melhor o quadro de encaminhamentos durante este mandato, colhemos informações de todas as fichas de 2001 a 2007. Depois de efetuado o levantamento dessas informações, filtramos apenas os anos de 2005 a 2007 que corresponderiam ao último mandato. No emaranhado de $1.420^{5}$ casos, atendidos durante esse último período citado, 250 diziam respeito a casos encaminhados por escolas. 
Diante desse número significativo, deparamo-nos com mais um elemento que demonstrou essa intensa busca do Conselho Tutelar por parte da escola. Pensamos essa situação como um triângulo no qual o Conselho, escola e familiares/ crianças seriam três vértices. A demanda que foi formulada em um deles, no caso a escola, levou-nos a indagar sobre as narrativas e os atravessamentos que poderiam ser depreendidos por parte das conselheiras envolvidas nesse processo. $\mathrm{O}$ intuito é compreender quais e como tem sido feitas essas demandas. Levamos em conta que o Estatuto da Criança e do Adolescente prevê situações em que a escola deverá realizar encaminhamentos ao Conselho Tutelar, entretanto, temos nos deparado com uma série de ações que vão de encontro ao que prevê o Estatuto.

Para ouvirmos as conselheiras, contamos com um roteiro de entrevista semiestruturado que funcionou como um elemento norteador. Utilizamos um gravador que contribuiu para um melhor registro das informações durante a entrevista. Também disponibilizamos um Termo de Consentimento Livre e Esclarecido, convidando os entrevistados a autorizarem a realização da entrevista, mantendo em sigilo o nome das entrevistadas.

\section{A fala das Conselheiras}

Os dados produzidos ${ }^{6}$ durante as entrevistas com as conselheiras foram analisados de forma conjunta, não se diferenciando a fala de uma ou outra conselheira. Entendemos que assim estaríamos levando em conta a postura das conselheiras e não as ações individuais de cada uma.

Em Cariacica, os conselheiros recebem um pró-labore de R $\$ 900,00$ e, diante das peculiaridades locais, consideram o trabalho um desafio constante. Muitas vezes não são bem-vindos nos locais em que precisam comparecer e possuem poucos serviços de retaguarda que os auxiliem nas tarefas cotidianas. É importante ressaltar que toda a infraestrutura do Conselho Tutelar, no Estatuto da Criança e do Adolescente, deve ser respaldada pela prefeitura, por meio de lei municipal. Todavia, no cotidiano de trabalho isso não tem se efetivado e diante desses obstáculos e, também, do desprovimento de recursos para resolução dos casos, o trabalho torna-se desgastante.

As conselheiras, tomadas diversas vezes por juízo de valor, têm nomeado muitos pais como negligentes em relação ao acompanhamento da vida escolar. Esse tipo de postura dos pais acaba transformando-se em caso de Conselho Tutelar, pois na maioria das vezes, eles não comparecem à escola quando são convocados, conforme o depoimento de uma ex-conselheira:

Os pais não estão acompanhando os filhos na escola. Se a criança está com dificuldade, é agressiva, não respeita professor, não faz as tarefas. Os pais são chamados na escola, porém muitos não comparecem e isso se torna caso de Conselho Tutelar. Quando a família não atende ao chamado do Conselho Tutelar, o caso é encaminhado para o Ministério Público. Isso acontece porque o Conselho Tutelar notificou 
e a família não atendeu à notificação. Então, uma coisa que poderia ser resolvida facilmente, vira um processo (EXCONSELHEIRA).

Scheinvar e Nascimento (2007), trabalhando a questão da jurisdicionalização das práticas ${ }^{7}$ do Conselho Tutelar, afirmam que os conselheiros, comumente, têm definido as condutas familiares, utilizando-se, para isso, de práticas jurídicas. No Brasil, o atendimento às crianças e aos jovens vem sendo tradicionalmente realizado por entidades de assistência ou pelo judiciário, sendo que a justiça sentencia e os equipamentos sociais executam as políticas de assistência. Entretanto, tem sido feitos julgamentos sobre as pessoas e sobre suas vidas e não das condições sociais em que vivem.

É importante destacar que o Conselho Tutelar não julga, quem o faz é o Poder Judiciário. O Conselho Tutelar tem em suas atribuições a realização de inquéritos sociais e a realização de encaminhamentos, observando não apenas leis, mas também normas que são negociadas no cotidiano. Partindo dessa forma de atuação, entendemos que é possível a reivindicação política, também pautada em leis, mas que não emitem sentenças e nem apontam medidas particulares.

Para as conselheiras, a rebeldia apresentada pelos alunos é entendida como consequência de uma má educação recebida, fruto da saída das mães de dentro dos lares para o mundo do trabalho. Badinter (1980) mostra que a imagem da "mãe ideal" foi uma construção histórico-social. Essa sacralização da figura da mãe surge como uma forma de reprimir o poder e a autonomia da mulher por meio de um discurso que a culpará e a ameaçará, caso não cumpra o seu dever materno dito natural e espontâneo. Esse pensamento foi consolidado como discurso científico pela psicanálise, que colocou a mãe como responsável por toda e qualquer perturbação psíquica que a criança viesse a apresentar.

As conselheiras trazem essa visão do papel da mãe como algo imaculado e incondicional que tem importantes consequências no exercício da convivência com seus filhos. Dessa forma, descrevem que:

Antigamente as mães trabalhavam dentro de casa para lavar, passar, cozinhar e cuidar de menino. Viviam às vezes só com um salário mínimo e passavam até dificuldade, mas a mãe estava ali cuidando. Arregaçamos as mangas e fomos trabalhar fora e deixamos os nossos filhos em casa sozinhos. Então em casa ele aprende o que ele quer, faz o que ele quer, aí cresce aquela criança sem limite, sem rédea, sem respeito por ninguém. Quando ele chega na sala de aula faz e acontece. Aí existe um professor despreparado, é um conjunto (EX-CONSELHEIRA).

Outro dado trazido pelas conselheiras, sobre a atuação diante da rebeldia que tem sido observada nos alunos, é a confusão entre as atividades exercidas pelo Conselho e pela polícia, por conta de que algumas vezes atuam em parceria: 
Qualquer lugar que manda uma notificação ao Conselho Tutelar é bem atendido. O único lugar que ainda não recebe muito bem a notificação é a escola. Na escola, eles já nos recebem de uma forma abusada. Porque quando eles precisam da gente, chamam na mesma hora, quando eles tinham alunos com problema, nós íamos na mesma hora com os policiais da SEDU. E eu trabalhava com o cabo Silva, aí eu o chamava para intimidar, porque adolescente a gente tem que estar intimidando de alguma forma, ele tem que ter medo de alguma coisa. Eu aprendi isso: se não tiver medo de nada, você não consegue barrá-lo (EX-CONSELHEIRA).

No interior das escolas, as conselheiras têm apaziguado brigas entre alunos, briga de aluno com professor e, ainda, averiguado a destruição do patrimônio escolar por parte dos alunos. Diversos casos, que deveriam ser encaminhados para outros órgãos públicos são resolvidos pelas próprias conselheiras.

As conselheiras relataram que encaminham muitos casos de rebeldia e violência a um psicólogo, buscando, dentro dos precários serviços públicos de saúde, encontrar um lugar para essas crianças e adolescentes. Compreendemos esse tipo de atuação como sendo uma solução paliativa e que gera alívio no cotidiano de trabalho, porém implica uma série de questões que levam as demandas a serem tratadas de forma individual e restritas ao campo da psicologia. Ou seja, estabelece um cotidiano esvaziado politicamente e tornam invisíveis as formas de dominação e exploração. Tais demandas passam a ser atribuídas ao campo do psiquismo entendido como próprio da vida interior do sujeito. Com isso, conflitos e demandas são transformados em patologias.

Como parte dessa busca por uma solução, indicam também a procura de ajuda médica em Unidades de Saúde, Centro de Prevenção e Tratamento de Toxicômanos (CPTT) ${ }^{8}$ Alcoólicos Anônimos e em algumas organizações não governamentais mantidas por entidades religiosas. Dentro desse restrito leque de possibilidades de auxílio às crianças e adolescentes, alguns são avaliados como inapropriados pelas conselheiras.

Naquela ONG, eles tratam meninos como animais. Os meninos falam comigo: 'Tia, eu fico na rua, mas não volto pra lá'. Lá tem um pastor, que fala que é pastor e bate nas crianças e nos adolescentes. Isso é jeito de cuidar? Só ficam lá aqueles que são de longe, porque não teriam para onde ir. Aqueles que são de perto não ficam porque todos são tratados como bichos (EX-CONSELHEIRA).

Um tempo atrás, na Casa de Passagem, eu quase bati no porteiro porque ele pegou um menino pequeno pelo cabelo e saiu arrastando. Eu perguntei: "Porque você não puxa o meu cabelo?". Vê se isso é jeito de tratar uma criança! O menino está longe de casa, sem pai, sem mãe, sem irmão, maltratado, comendo de qualquer jeito e dormindo de 
qualquer jeito no chão. Eu evitava ao máximo colocar lá, colocava na casa de qualquer parente, mas Casa de Passagem para mim era o último caso, só se não tivesse lugar mesmo (EX-CONSELHEIRA).

Diante desses discursos, ressaltamos que as conselheiras têm atuado com o mínimo necessário. Entretanto, é importante lembrar que uma das atribuições das conselheiras é, justamente, de exigir junto ao município, com o Conselho $\mathrm{Mu}$ nicipal de Direitos da Criança e do Adolescente, a criação de políticas públicas. Faz-se necessário uma atuação mais política e articulada com outros segmentos, ou seja, ações que garantam estratégias políticas e espaços de participação na formulação, fiscalização e no controle das ações e decisões do Estado.

Outro ponto que destacamos, é o fato de que no Conselho é muito comum o discurso de que a estrutura familiar teria grande participação no desenvolvimento escolar do aluno. As conselheiras têm se baseado no ideal de família burguesa, tratada por Donzelot (1980) que fala de uma família centrada em si mesma, na qual os pais devem zelar pelos filhos. Ao acompanhar a próxima fala, é possível notar como esse ideal tem se colocado fortemente nas práticas cotidianas das conselheiras.

A situação é muito complicada porque muitas crianças e adolescentes vêm de uma família que não tem estrutura nenhuma. Muitas vezes vêm de família que está envolvida com droga, alcoolismo, prostituição e isso tudo na vida da criança. O pai matricula na escola e acha assim: 'A escola se vira'. E aí entrega ao professor. O pai deixa o seu filho na escola, mas não sabe o que está se passando dentro da escola. Às vezes o pai fala: 'Ah! Já não aguento mais esse menino, ele não me dá sossego' $E$ não vê que, na realidade, aquela criança está precisando de carinho, precisando da proteção dele e isso acaba refletindo no comportamento dela dentro da escola (EX-CONSELHEIRA).

Como na maioria dos casos de meninos indisciplinados, é feito o encaminhamento ao Conselho Tutelar. É nesse espaço que se espera que os problemas sejam resolvidos. Em diversos casos, notamos que a resolução do problema se dá pela determinação moral de como a mãe deve agir com o seu filho. Foucault (1996), em seus escritos sobre a teoria penal, trata a penalidade do século XIX como a do controle. A intenção era assegurar o controle dos indivíduos antes mesmo que cometessem algum desvio de norma. Entretanto, esse tipo de controle se daria em outro nível, o qual o Poder Judiciário não monopolizaria. ${ }^{9}$ É nesse instante que uma série de outros poderes laterais são incumbidos de executar a tarefa de correção e vigilância: a polícia para a vigilância e as instituições psicológicas, pedagógicas e médicas para a correção.

Muito semelhante às práticas vigentes na sociedade disciplinar, o Conselho Tutelar, assim como esses poderes laterais, também tem se colocado como um espaço de controle dos indivíduos que determina normas para o ajustamento social. Nas palavras de Foucault, instituem regras para a "ortopedia social". 
A partir dos dados, entendemos que a escola tem buscado aliados para continuar existindo e, nessa tentativa, o Conselho tem servido para dar determinadas soluções aos casos urgentes, resolvendo questões desconectadas das práticas sociais e políticas, tratando-as de forma pontual. De modo geral, tem-se estruturado um jogo de empurra que, de fato, não resolve os incontáveis problemas, mas, por hora, tem servido de alívio para as instituições envolvidas.

\section{CONSIDERaÇões Finais}

Ao ouvirmos as falas das conselheiras, pudemos compreender de que forma, muitas vezes, os atendimentos têm sido conduzidos desde o momento em que a escola encaminha o aluno ao Conselho Tutelar até a chegada da família convocada ao Conselho. Foi com esse material que entendemos que os discursos estão permeados por um cotidiano psicologizado. Quando Coimbra (1995) estudou sobre as práticas "psi” nos anos 1970 no Brasil, ela descreveu essa psicologização como relações de poder que são transformadas em simples relações psicológicas existenciais. Em nossa pesquisa, em todos os casos, as crianças chegaram até o atendimento psicológico, porque seus problemas eram entendidos e, muitas vezes, sentidos, como de ordem puramente psicológica, individual e/ou familiar e penal.

Coimbra (1995), ainda nesse estudo, afirma que no Brasil a crença em uma essência do indivíduo foi fortalecida e amplamente divulgada no período da ditadura militar, mais especificamente, a partir do final dos anos 1960, quando ocorreu o boom da psicologia, da psicanálise e das faculdades particulares. Nessa época, o familiarismo e também o intimismo ganharam destaque. Nesse cenário, toda e qualquer problemática tornava-se reduzida à questão familiar. $\mathrm{O}$ intimismo que se liga à psicologização e ao familiarismo fortalece e produz um sujeito voltado para dentro de si mesmo, em que os espaços públicos são inferiorizados e desqualificados e o que passa a ser importante é só o espaço do privado.

Quando ouvimos das conselheiras sobre as formas de atuação dos psicólogos, entendemos esses profissionais como herdeiros dessas práticas comuns na década de 1970, nomeado por Coimbra, como "Guardiães da Ordem". Mas também temos notado que, antes mesmo que se encaminhe uma criança ao psicólogo, já existe um discurso psicologizado dentro das famílias e dentro do Conselho. Postura que tem persistido em vários âmbitos e que leva em conta um pensamento que não analisa as ações em questão.

Como explicitado no estudo de Patto (1999), e também em nosso estudo, vimos uma experiência escolar avaliada sem que se considerem as singularidades do aluno extramuro escolar. Dentro do Conselho, há pessoas informadas por pseudoconhecimentos científicos que culpam os alunos pelo fracasso escolar. Essas práticas ainda têm sido disseminadas e apropriadas pelas famílias que utilizam o serviço do Conselho Tutelar.

Há uma participação ativa dos profissionais, como diretores, professores, pedagogos, psicólogos, médicos, no processo de estigmatizar e discriminar o aluno. Patto (1999), também identifica, de outro lado, na fala das mães, juntamente com a valorização da escola, sentimentos de ilegitimidade, insucesso e uma perplexidade diante do fracasso escolar dos filhos. 
Numa atribuição de responsabilidades, desconsideram-se as desigualdades de oportunidades e as construções históricas, o que impossibilita a visão da complexidade social envolvida neste cenário. Assim, o fracasso passa a ser devido unicamente a questões individuais como a falta de esforço, de dedicação, de capacidade pessoal e outras (PATTO, 1999).

Um conceito que sobressaiu em nosso estudo foi o de família. A noção de família "estruturada" tem perpassado por todos os espaços. Entretanto, para entender esse jogo de culpabilização sobre as famílias que não seguem o padrão nuclear, é necessário situar a emergência e a consolidação dessa forma de organização familiar, a família nuclear burguesa (ARIÈS, 1978; DONZELOT, 1980).

Muitos encaminhamentos de meninos "indisciplinados" têm sido feitos pela escola. Pensamos que essa noção de indisciplina precisa ser repensada, pois ela tem circulado por muitos espaços e tem produzido crianças dentro de uma lógica, que muitas vezes, idealiza o menino dentro de sala de aula. Tem-se baseado em um modelo de normalidade no qual as diferenças são compreendidas como desigualdades.

As ações diante desses encaminhamentos têm sido executadas de forma pulverizada. Ou seja, as ações acabam sendo realizadas apenas por um conselheiro que toma muitas decisões sobre determinados casos de maneira individual. Essas posturas enfraquecem a atuação do Conselho e, ainda, reproduzem outras práticas menos interessantes.

Os conselheiros, por sua vez, contam com uma precariedade de condições do trabalho. Eles tem se deparado com uma rede de equipamentos sociais que não tem lhes auxiliado na garantia efetiva dos direitos da criança e do adolescente. Apesar dessas diversas questões, o Conselho tem sido um mediador dos problemas da comunidade em geral. Ele tem se colocado próximo a ela e acolhido certo desespero diante de problemas que, sozinhos, esses diferentes espaços, não têm meios de resolver.

Por outro lado, vemos também uma escola enfrentando situações de conflito, tendo que lidar, em alguns casos, com adolescentes armados, o que tem causado medo e impotência nos profissionais da educação. A escola tem buscado formas de alívio para essas dificuldades cotidianas e, nessa tarefa, tem solicitado inúmeras vezes a presença do Conselho. Essa postura, em vários casos, demonstra um desconhecimento do trabalho do Conselho, mas, ao mesmo tempo mostra que o Conselho tem feito parte do cotidiano. Ele tem sido incluído como um órgão de apoio no contato com crianças e adolescentes.

É importante, também, relembrarmos que o Conselho Tutelar, que é um órgão de garantia de direitos, está inserido numa rede que também tem essa função. Dessa forma, é necessário colocar em pauta como o Conselho tem sido entendido, bem como quais funções têm sido delegadas a ele. Muito comumente têm sido realizadas ações assistencialistas, religiosas, moralistas e punitivas, marcando esse 
espaço com práticas individualistas e culpabilizantes. Seguindo essa prática, a sociedade, de forma geral, tem perdido o espaço de fala e de reivindicação que foi conquistado em 1990, quando o Estatuto foi promulgado.

Há uma série de incongruências que circulam no interior do triângulo formado por Conselho Tutelar, escola e família. Para este estudo, focamos, basicamente, o Conselho e a família, tendo a escola como promotora dessa relação e também como colaboradora da configuração desse contato. Em suma, entre Conselho Tutelar e família, compreendemos uma relação marcada pela psicologização, pelo discurso competente, pelo intimismo, pelo familiarismo e, por fim, compreendemos que tem se formado um campo de forças no qual a criança é empurrada para os diversos espaços que produzem e reproduzem os comportamentos considerados inaceitáveis.

O Conselho Tutelar tem produzido demandas por meio de suas práticas diárias. Dessa forma, entendemos que não há, necessariamente, um desconhecimento sobre as atividades que o Conselho tem exercido. Família, escola e demais usuários do serviço têm se apropriado dessas práticas produzidas na resolução dos problemas cotidianos. Os efeitos dessas práticas exercidas e veiculadas nos remetem diretamente a pensar na grande diferença que tem se estabelecido entre a prescrição da ação dos conselheiros e ações reais exercidas por eles.

Não se trata de padronizar o lugar ou atribuir uma natureza à função do conselheiro, da mãe, do pai ou da criança, mas de questionar quais processos de subjetivação ${ }^{10}$ têm sido produzidos nessas relações. É necessário apreender esse processo em sua complexidade. Nosso objetivo, sem dúvida, seguindo nossa linha de pensamento, não se ocupa em nomear culpados ou responsáveis. Disponibilizamo-nos a partir não do objeto, mas das práticas que os têm constituído.

Destacamos que esses espaços compõem uma rede que se inter-relaciona e, quando cada um desses componentes atua de forma solitária, suas ações acabam se tornando desconectadas da realidade. Pensamos que é preciso promover o fortalecimento dessas redes de relações (escola, família, Conselho, governo etc.) e a construção de estratégias que busquem a melhoria dos serviços que auxiliem na atuação dos conselheiros tutelares, o que poderá acarretar uma maior garantia dos direitos da criança e do adolescente.

\section{Notas}

${ }^{1}$ A genealogia, termo tomado de Nietzsche, é definida por Foucault como uma metodologia que se opõe a pesquisa da "origem". Foucault $(2008$, p.171) "[...] delineou-se assim o que se poderia chamar uma genealogia, ou melhor, pesquisas genealógicas múltiplas, ao mesmo tempo redescoberta exata das lutas e memória bruta dos combates. E esta genealogia, como acoplamento do saber erudito e do saber das pessoas, só foi possível e só se pôde tentar realizá-la à condição de que fosse eliminada a tirania dos discursos englobantes com suas hierarquias e com os privilégios da vanguarda teórica".

${ }^{2}$ Esse órgão foi extinto. Atualmente funciona a Unidade de Integração Social (UNIS) do Instituto da Criança e do Adolescente do Espírito Santo (ICAES).

${ }^{3}$ Orçamento Participativo é um mecanismo governamental que permite aos cidadãos influenciar ou decidir sobre os orçamentos públicos, geralmente o orçamento de investimentos de prefeituras municipais, por meio de processos de participação cidadã. Esses processos costumam contar com 
assembléias abertas e periódicas e etapas de negociação direta com o governo. Essa nova política começou a se configurar a partir do ano de 2004 com a entrada do Partido dos Trabalhadores na prefeitura desse município. (PREFEITURA DE CARIACICA, 2008).

${ }^{4}$ Rey (2005); Alves-Mazzotti e Gewandsznajder (1998).

${ }^{5}$ Os outros 1.170 casos referem-se a casos variados, como abuso sexual, rebeldia, dependência química, negligência dos pais, problemas de doença, agressão, exploração sexual, maus-tratos, dentre outros que foram encaminhados para o Conselho Tutelar por meio de denúncia anônima, pelo pai, pela mãe, pelo irmão, pelo vizinho ou outros.

${ }^{6}$ Optamos por utilizar o termo "produção de dados", pois a partir dos recentes estudos acerca da cognição, numa perspectiva construtivista, não há coleta de dados, mas, desde o início, uma produção dos dados da pesquisa. Segundo Kastrup (2007), a formulação paradoxal de uma "produção dos dados" visa ressaltar que há uma real produção, mas do que, em alguma medida, já estava lá de modo virtual.

${ }^{7}$ A jurisdicionalização das práticas fala da “[...] presença de modelos de atuação característicos do Poder Judiciário, que acabam sendo adotados, mesmo em espaços que não detêm tal poder, mas que, por serem revestidos de certa autoridade e terem como fundamento para a sua prática o termo da lei, assumem tais formas como as adequadas para o seu exercício. Do nosso ponto de vista, é esta a lógica que tem pautado algumas das práticas dos Conselhos Tutelares" (SCHEINVAR; NASCIMENTO, 2007, p. 153).

${ }^{8}$ Esse serviço localiza-se em Vitória.

${ }^{9}$ Foucault (2003) esclarece que o Poder Judiciário atua na reação penal diante de certos atos considerados infracionais, não sendo possível a ele "corrigir as virtualidades" dos indivíduos.

${ }^{10}$ Segundo Foucault (1984), o termo subjetivação designa os modos pelos quais nos tornamos sujeitos. Os modos de subjetivação aparecem e se desenvolvem historicamente como práticas de si dentro de práticas discursivas (saberes) e práticas de poder, que testemunham a descontinuidade de suas formas históricas.

\section{REFERÊNCIAS}

ALVEZ-MAZZOTTI, A. J.; GEWANDSZNAJADER, F. O método nas ciências naturais: pesquisa quantitativa e qualitativa. São Paulo: Pioneira, 1998.

ARIÈS, P. História social da criança e da família. Rio de Janeiro: Zahar, 1978.

BADINTER, E. Um amor conquistado: o mito do amor materno. São Paulo: Círculo do Livro, 1980.

COIMBRA, C. Guardiães da ordem: uma viagem pelas práticas psi no Brasil do "Milagre". Rio de Janeiro: Oficina do Autor, 1995.

DELEUZE, G.; GUATARRI, Félix. Mil platôs - capitalismo e esquizofrenia. v. 1. Rio de Janeiro: Editora 34, 1995.

DONZELOT, J. A polícia das famílias. 2. Ed. Rio de Janeiro: Edições Graal, 1980.

FOUCAULT, M. História da sexualidade: o uso dos prazeres. Rio de Janeiro: Graal. 1984.

FOUCAULT, M. A verdade e as formas jurídicas. Rio de Janeiro: PUC e NAU, 1996. 
FOUCAULT, M. Vigiar e punir. Petrópolis: Editora Vozes, 2003.

FOUCAULT, M. Microfísica do Poder. 26 ed. Rio de Janeiro: Graal, 2008.

INSTITUTO BRASILEIRO DE GEOGRAFIA E ESTATÍSTICA - IBGE. 2007. Disponível em: $<$ http://www.ibge.gov.br/cidadesat /topwin dow.htm?1>. Acesso em: 9 jun. 2008.

KASTRUP, V. O funcionamento da atenção no trabalho do cartógrafo. In: Psicologia e Sociedade, Porto Alegre, v. 19, n. 1, jan./abr. 2007. p. 15-22.

PATTO, M. H. S. A produção do fracasso escolar: histórias de submissão e rebeldia. São Paulo: Casa do Psicólogo, 1999.

PREFEITURA DE CARIACICA. Disponível em: <http://www.cariacica.es.gov. br/>. Acesso em: 5 dez 2008.

REY, F. G. Pesquisa qualitativa e subjetividade. São Paulo: Pioneira Thomson Learning, 2005.

SCHEINVAR, E.; NASCIMENTO, M. L. do. De como as práticas do Conselho Tutelar vêm se tornando jurisdicionais. Aletheia, Canoas, n. 25, jan./jun. 2007. p.152-162.

Recebido em: agosto de 2009 Aceito em: fevereiro de 2011 